\title{
WRIST AND PALM INDEXES IN CARPAL TUNNEL SYNDROME
}

\author{
JOAO ARIS KOUYOUMDJIAN*, MARIA PENHA ANANIAS MORITA**, \\ PAULO RICARDO FERNANDO ROCHA ***, RAFAEL CARLOS MIRANDA***, GUSTAVO MACIEL GOUVEIA***
}

\begin{abstract}
According to median sensory latency $\geq 3.7 \mathrm{~ms}$ (wrist-index finger [WIF], $14 \mathrm{~cm}$ ), median/ulnar sensory latency difference to ring finger $\geq 0.5 \mathrm{~ms}(14 \mathrm{~cm})$ or median midpalm $(8 \mathrm{~cm})$ latency $\geq 2.3 \mathrm{~ms}$ (all peakmeasured), 141 Brazilian symptomatic patients (238 hands) have CTS confirmation. Wrist ratio (depth divided by width, WR) and a new wrist/palm ratio (wrist depth divided by the distance between distal wrist crease to the third digit metacarpophalangeal crease, WPR) were measured in all cases. Previous surgery/peripheral neuropathy were excluded; mean age 50.3 years; $90.8 \%$ female. Control subjects (486 hands) have mean age 43.0 years; $96.7 \%$ female. The mean WR in controls was 0.694 against $0.699,0.703,0.707$ and 0.721 in CTS groups of progressive WIF severity. The mean WPR in controls was 0.374 against $0.376,0.382,0.387$ and 0.403 in CTS groups of WIF progressive severity. Both were statistically significant for the last two groups (WIF $>4.4 \mathrm{~ms}$, moderate, and, WIF unrecordable, severe). BMI increases togetherwith CTS severity and WR. It was concluded that both WR/WPR have a progressive correlation with the severity of CTS but with statistically significance only in groups moderate and severe. In these groups both WR and BMI have progressive increase and we believe that the latter could be a risk factor as important as important WR/WPR.
\end{abstract}

KEY WORDS: carpal tunnel syndrome, median nerve, compressive neuropathy, wrist and palm ratio, wrist and hand dimension.

\section{Índices de palma/punho e síndrome do túnel do carpo}

RESUMO - Um grupo de 141 pacientes (238 mãos) com síndrome do túnel do carpo (STC) sintomático foi estudado após confirmação por condução nervosa: latência distal sensitiva do nervo mediano (LDS-M) $\geq 3,7 \mathrm{~ms}$ (punho - II dedo, $14 \mathrm{~cm}$ ), diferença de latência sensitiva mediano-ulnar $\geq 0,5 \mathrm{~ms}$ (punho - IV dedo, $14 \mathrm{~cm}$ ) e/ou latência palma-punho do nervo mediano $\geq 2,3 \mathrm{~ms}(8 \mathrm{~cm})$; as latências foram medidas no pico do potencial. Todos os casos tiveram as seguintes medidas calculadas: 1. Índice do punho (IP, espessura dividido pela largura do punho); 2. Índice punho-palma (IPP, espessura do punho dividido pela distância entre a prega distal do punho e a prega mais proximal do III dedo); a média de idade foi de 50,3 anos com 90,8\% do gênero feminino. Foram realizadas mesmas medidas em 486 mãos do grupo controle (GC) cuja idade média foi 43,0 anos e $96,7 \%$ do gênero feminino. O IP médio do GC foi de 0,694 contra 0,699/0,703/0,707/0,721 do grupo STC (valores relativos a casos incipiente/leve/moderado/grave). O IPP médio do GC foi de 0,374 contra $0,376 / 0,382 / 0,387 / 0,403$ do grupo STC. Ambos os índices apresentaram significância estatística na comparação com STC mais grave (moderado: LDS-M > 4,4 ms e grave: LDS-M não obtida). $\mathrm{O}$ índice de massa corporal aumentou de acordo com a gravidade do STC e o IP. Conclui-se que tanto o IP como o IPP apresentam correlação progressiva com a gravidade do STC porém com significância estatística apenas nos grupos moderado e grave. Neste grupos tanto o IP como o índice de massa corporal tiveram aumento progressivo e acreditamos que o último possa representar risco tão importante quanto IP/IPP.

PALAVRAS-CHAVE: síndrome do túnel do carpo, nervo mediano, neuropatia compressiva, dimensões do punho, condução nervosa.

Department of Neurological Sciences, Electroneuromyography Section, Medical School, Sao Jose Rio Preto, Sao Paulo, Brazil; *MD, MSc, Assistant-Professor; **MD, MSc; ***Graduate medical students. Presented on $46^{\text {th }}$ American Association of Electrodiagnostic Medicine Scientific Meeting, Vancouver, Canada, October 6-9, 1999. Aceite: 20-abril-2000.

Dr. Joao Aris Kouyoumdjian - Av. Bady Bassitt 3896 - 15025-000 São José Rio Preto SP - Brasil. E-mail: jaris@zaz.com.br 
Carpal tunnel syndrome (CTS) is the most common entrapment neuropathy in upper limbs. It is due to compression of the median nerve as it passes beneath the transverse carpal ligament and the majority of patients presents with nocturnal numbness, paraesthesia and pain in hands. Johnson et al. ${ }^{1}$ in 1983 correlated wrist dimensions with median sensory latencies in CTS cases and suggest that the squarer the wrist the longer the latencies. As the wrist depth to width ratio (wrist ratio, WR) approaches 0.70 the median sensory peak-latency (wrist to third digit, $14 \mathrm{~cm}$ ) is likely to surpass 3.7 $\mathrm{ms}$, the upper limits of the usually considered normal latency. Kuhlman \& Hennessey ${ }^{2}$ in 1997 found a square-shaped wrist (WR $\geq 0.70)$ as the most sensitive $(69 \%)$ among six signs in detecting CTS; the specificity of this sign was $73 \%$. Measurement of WR would be recommended as a part of the physical examination for CTS and its presence is supportive of CTS in most cases.

The present study was performed in a Brazilian population to study WR and also a new wrist to palm index in CTS and controls subjects.

\section{METHOD}

\section{CTS subjects}

From September 1998 to January 1999, 141 consecutive subjects referred for electrodiagnostic consultation for CTS confirmation were included. All subjects were symptomatic and at least nocturnal and/or awakening numbness and/or paraesthesia in one or both hands were found. Hands with previous CTS surgery and subjects with clinical or electrophysiological evidence of generalized neuropathy were excluded from the study. Subjects with diabetes mellitus were not excluded unless their electrophysiological examination demonstrated a generalized peripheral neuropathy. From the total 141 subjects included in the study, 97 have bilateral CTS confirmation (68.8\%), 29 have right CTS $(20.6 \%)$ and 15 have left CTS $(10.6 \%)$; therefore, 238 hands were included in the study. The mean age was 50.3 years, ranging from 26 to 79 . There were 128 women $(90.8 \%)$ and 13 men $(9.2 \%)$ in the study.

\section{Control subjects}

Two hundred forty three asymptomatic controls ( 486 hands) have their wrist and palm dimensions measured and also the ratios calculated. The mean age was 43.0 years, ranging from 17 to 86 . There were 235 women (96.7\%) and 8 men (3.3\%) in the study. The protocol was approved by the local ethics committee of our institution, and all subjects gave their informed consent to have their measures taken in the study.

\section{Wrist/palm dimensions and body mass index}

The anteroposterior dimension (depth in $\mathrm{mm}$ ) and mediolateral dimension (width in $\mathrm{mm}$ ) of the wrist were measured at the distal flexor wrist crease using a standard sliding caliper. A WR was calculated dividing depth by width (Johnson's index). Palm length measure in mm was taken from distal flexor wrist crease to the third digit metacarpophalangeal crease. A new ratio was calculated dividing wrist depth by palm length (new index proposed, wrist-palm ratio, WPR). In order to avoid bias from different 5 examinators measuring CTS and controls subjects, we performed a blind wrist measurement session with 15 subjects ( 30 hands). All 5 authors measured the same wrists; the WR was calculated and the p-value was found not significant among them (Table 1). Body mass index (BMI), a good general indicator of body fat content, was calculated as weight (kilograms) divided by height (meters) squared $\left(\mathrm{kg} / \mathrm{m}^{2}\right)$.

\section{Nerve conduction studies}

Standard nerve conduction studies were performed on CTS subjects by the first 2 authors (JAK/MPAM) using DANTEC, Cantata (Denmark), and, LBM (USA) for the recordings, and, at least one abnormal test was found among three described at the following. Sensory nerve conduction studies were performed antidromically.

Wrist to index finger (WIF): the stimulus ( $0.05 \mathrm{~ms}$ duration) was applied at the wrist, $14 \mathrm{~cm}$ proximal to the active recording at the index finger (ring electrodes). The sweep speed was set at $2 \mathrm{~ms} / \mathrm{div}$ with the gain at 10 $20 \mathrm{uV} / \mathrm{div}$. The latency was measured to the peak of the evoked sensory nerve action potential and values equal or above $3.70 \mathrm{~ms}$ were considered abnormal.

Median to ulnar peak difference (MUD): the stimulus ( $0.05 \mathrm{~ms}$ duration) was applied at the wrist, $14 \mathrm{~cm}$ proximal to the active recording at the ring finger (ring electrodes). The sweep speed was set at $2 \mathrm{~ms} / \mathrm{div}$ with the gain at 10-20 uV/div. The peak latency difference between median and ulnar evoked sensory nerve action potentials was calculated and values equal or above $0.50 \mathrm{~ms}$ were considered abnormal. Mixed nerve conduction study was performed orthodromically. 
Median palmar latency (PW): the stimulus ( $0.05 \mathrm{~ms}$ duration) was applied at the midpalm, $8 \mathrm{~cm}$ distal to the active recording at the wrist (bar electrode). The sweep speed was set at $2 \mathrm{~ms} / \mathrm{div}$ with the gain at 10-20 uV/ div. The latency was measured to the peak of the evoked mixed nerve action potential and values equal or above $2.30 \mathrm{~ms}$ were considered abnormal. Palmar temperature was maintained above $31^{\circ} \mathrm{C}$ using digital thermometer (BRAILE BIOMEDICA, Brazil).

\section{Groups}

WIF was used to define CTS severity and four groups were constituted according to peak-latency as described above. Incipient: 2.9 to $3.6 \mathrm{~ms}$ (normal WIF values but abnormal MUD and/or PW); Mild: 3.7 to 4.4 ms; Moderate: > $4.4 \mathrm{~ms}$; and Severe: unrecordable sensory nerve action potential.

\section{Statistics}

Student's t test was used to compare the difference between means for the variables in controls subjects and CTS groups.

\section{RESULTS}

The results are shown on Table 2. Control subjects have a mean WR of $0.694 \pm 0.038$ and WPR of $0.374 \pm 0.033$. CTS cases have a mean WR ranging from 0.699 to 0.721 and a WPR ranging from 0.376 to 0.403 according to WIF severity (groups described above). On both indexes there were a significant progressive correlation with the severity of CTS. P-values $<0.001$ were found in moderate and severe groups. WR $\geq 0.70$ was found in $51.7 \%$ of CTS hands and in $45.9 \%$ of the controls subjects hands (comparison of proportion, $\mathrm{p}=0.164$ ). WR $\geq 0.75$ was found in $15.1 \%$ of $\mathrm{CTS}$ hands and in $7.4 \%$ of the controls subjects hands (comparison of proportion, $\mathrm{p}=0.002$ ). Mean BMI, another personal risk factor described for CTS, was also higher in CTS group as put on Table 3 for right hands. BMI showed a slight progression following WR increase: $\mathrm{WR} \geq 0.75$ (BMI $=$ $29.4)$, $\mathrm{WR}<0.75$ and $\geq 0.70(\mathrm{BMI}=28.4)$ and $\mathrm{WR}<0.70(\mathrm{BMI}=27.8)$.

Table 1. P-value of wrist ratio among the 5 authors in 30 hands.

\begin{tabular}{cccccc}
\hline Author & JAK & MPAM & RCM & GMG & PRFR \\
\hline JAK & - & 0.396 & 1.000 & 0.396 & 0.396 \\
MPAM & 0.396 & - & 0.396 & 1.000 & 1.000 \\
RCM & 1.000 & 0.396 & - & 0.396 & 0.396 \\
GMG & 0.396 & 1.000 & 0.396 & - & 1.000 \\
PRFR & 0.396 & 1.000 & 0.396 & 1.000 & - \\
\hline
\end{tabular}

Table 2. WR and WPR in controls and CTS subjects.

\begin{tabular}{lccccc}
\hline & Hands & $\begin{array}{c}\text { WR } \\
\text { Mean (SD) }\end{array}$ & p & $\begin{array}{c}\text { WPR } \\
\text { Mean (SD) }\end{array}$ & p \\
\hline Control subjects & 486 & $0.694(0.038)$ & - & $0.374(0.033)$ & - \\
WIF 2.9 to 3.6 ms & 69 & $0.699(0.041)$ & 0.312 & $0.376(0.034)$ & 0.639 \\
WIF 3.7 to 4.4 ms & 81 & $0.703(0.039)$ & 0.050 & $0.382(0.025)$ & 0.038 \\
WIF > 4.4 ms & 69 & $0.707(0.042)$ & 0.009 & $0.387(0.037)$ & 0.003 \\
WIF unrecordable & 19 & $0.721(0.039)$ & 0.003 & $0.403(0.037)$ & 0.000 \\
\hline
\end{tabular}

WR, wrist ratio; WPR, wrist-palm ratio; SD, standard deviation; CTS, carpal tunnel syndrome; WIF, wrist to index finger (median sensory peak-latency, $14 \mathrm{~cm}$ ). 
Table 3. WR and BMI in CTS and control subjects (right hands)

\begin{tabular}{ccccc}
\hline WR & CTS & Controls & BMI-CTS & BMI-Controls \\
\hline$\geq 0.75$ & $15.8 \%$ & $7.4 \%$ & $29.4 \pm 3.92$ & $24.2 \pm 4.55$ \\
& $(\mathrm{n}=20)$ & $(\mathrm{n}=18)$ & $(21.6-36.1)$ & $(16.0-34.9)$ \\
$<0.75$ and $\geq 0.70$ & $33.3 \%$ & $36.6 \%$ & $28.4 \pm 4.88$ & $25.7 \pm 4.67$ \\
& $(\mathrm{n}=42)$ & $(\mathrm{n}=89)$ & $(20.8-38.9)$ & $(17.3-38.9)$ \\
$<0.70$ & $50.7 \%$ & $55.9 \%$ & $27.8 \pm 4.16$ & $25.3 \pm 4.92$ \\
& $(\mathrm{n}=64)$ & $(\mathrm{n}=136)$ & $(19.6-41.2)$ & $(16.2-43.9)$ \\
\hline
\end{tabular}

WR, wrist ratio; CTS, carpal tunnel syndrome; BMI, body mass index.

\section{DISCUSSION}

Johnson et al. ${ }^{1}$ in 1983 were the first to correlate wrist dimension with CTS in 29 men (9 CTS and 20 control subjects) and 38 women (18 CTS and 20 control subjects). General observations suggested that a $0.70 \mathrm{WR}$ may be the critical shape of the wrist at which latencies tend to reach the upper limits of normal, ie, the mean plus two standard deviation from normal $3.7 \mathrm{~ms}$. Bleecker et al. ${ }^{3}$ studying the role of carpal canal size as a risk factor for CTS found in a computer tomography images a cross-sectional area of $1.75 \mathrm{~cm}^{2}$ in affected 14 males workers, significantly smaller than the controls subjects $\left(2.53 \mathrm{~cm}^{2}\right)$. Wrist circumference and body mass weight were not a predictor of smallest carpal canal area. Winn \& Habes ${ }^{4}$ also studied the carpal tunnel area as a risk factor for CTS in 27 CTS cases and 34 control subjects. Five consecutive computer tomography slices at $5 \mathrm{~mm}$ intervals were made through the carpal canal and the measurements used were those from the wrist crease and approximately $12 \mathrm{~mm}$ and $25 \mathrm{~mm}$ distal to it. Their results failed to report smaller canal area in CTS patients; in fact, CTS had larger carpal canal areas than controls regardless hand (right/ left), gender or slice. The contradictory effects for canal size found between this study and earlier may indicate that another anatomical risk factor, independent of carpal canal size may underlie CTS.

Gordon et al. ${ }^{5}$ studying the WR correlation with CTS in industry found that $24 \%$ of employees with WR less than 0.70 developed CTS compared with $74 \%$ of the employees with WR $\geq 0.70$. The study was done over a 3-year period with 80 employees who developed symptoms compatible with CTS within 4-12 months of employment and were evaluated with standard electrodiagnostic techniques. Edwards ${ }^{6}$ emphasizes the Johnson's observation that WR of 0.65 (rectangular wrist) showed mostly normal electrical studies and above 0.70 (square wrist) showed mostly abnormal ones. Of the 100 employees who measured with a WR of 0.75 or above, 99 had developed CTS within 6 months. Stetson et $\mathrm{al}^{7}$, studying the effects of age, gender, and anthropometric factors on nerve conduction measures in 105 healthy, asymptomatic adults without occupational exposure, found weak positive associations between WR $(0.61-0.78$, mean 0.68$)$ and both median sensory and motor latencies which were absent when WR was tested in single factor models. They do not recommend controlling for WR as a variable to nerve conduction studies. Nathan et al. ${ }^{8}$ found that WR was the third risk factor (body mass index and age being the first and second, respectively) for slowing of sensory conduction of the median nerve in a longitudinal study of CTS in industry. Radecki ${ }^{9}$ studied WR in 665 consecutive symptomatic patients with median abnormality based on either a median latency slowing at the carpal tunnel or a history of a prior carpal tunnel surgery. The mean WR without median abnormality was 0.672 in women and 0.655 in men. The mean WR with median abnormality was 0.704 in women and 0.681 in men. For those with WR $\geq 0.70,79 \%$ of women and $86.9 \%$ of men had median abnormality. Women had larger average WR than men, and the patients of each gender with a median abnormality had larger average WR than those of each gender without a median latency abnormality. The likelihood of a median abnormality was found to gradually increase as the average WR increased without an abrupt change in the relationship at 0.70 . The relationship between the average WR and the likelihood of a median abnormality appeared not to be affected by the occupation. 
Radecki ${ }^{10}$ performed electrodiagnostic studies in 1472 patients referred with upper-extremity symptoms. An increased WR was associated with prolongation of median latencies regardless workrelated complaints. He found mean WR being 0.685 in men and 0.709 in women with median slowing against 0.657 and 0.676 respectively without median slowing. Sposato et al. ${ }^{11}$ studying 417 railroad maintenance workers (375 males) found WR ranging from 0.600 to 0.828 . Of the 417 participants in the study, 40 were electrodiagnosed as abnormal (either bilaterally or unilaterally). No significant linear relationship was found between both nerve latency and WR of the right hands (males or females), suggesting that median motor and sensory nerve conduction latency values do not increase as wrist-squareness ratios increase. The WR parameter is not clinically useful for identifying workers with impaired median function or as a predictor for median distal mononeuropathies ${ }^{11}$. Nakamichi \& Tachibana ${ }^{12}$ studying 155 CTS cases and 272 control subjects found height and hands/third metacarpal length small or short in CTS group when compared to control one. Kuhlman \& Hennessey ${ }^{2}$ studying the sensitivity and specificity of 6 CTS signs in 143 cases found a square-shaped wrist as the highest sensitivity (69\%); they considered positive a WR $\geq$ 0.70 . Wrist squareness is the most objective sign because it is not based on subjective complaints and it cannot be influenced consciously by the subject. ${ }^{2}$

The present study made on a Brazilian population previously not described showed that incipient and mild CTS cases based on WIF have WR/WPR not statistically different from the control subjects. However, moderate and severe CTS cases have higher and statistically significant WR/WPR when compared to the control subjects. There was a clear increase in both ratios from control subjects to the most severe CTS group in spite of the first two CTS group being statistically not significant. We could not find a critical WR of 0.70 between CTS and controls subjects $(51.7 \%$ in CTS hands and $45.9 \%$ in control hands subjects). Only in high ratios (WR $\geq 0.75$ ) the difference was significant, but we can suppose that at this level BMI also contribute to increase incidence in CTS as showed our results with BMI increasing proportionaly to WR. The other ratio (WPR) proposed in our work was based on the possible suggestion that CTS patients could have small hands. If we hypothesized that wrist depth is larger in CTS patients and possibly palm length is shorter, then the ratio wrist depth/palm length could raise the sensitivity or at least add more precision to the classical Johnson's index (WR). Our results, as described above, showed that both ratios have about the same value and statistically significance. The factor or factors responsible for the significant association between an increased WR and the median abnormality remain to be elucidated. ${ }^{9}$

It is concluded that both wrist ratio and also wrist-palm ratio have a progressive correlation with the severity of CTS but with statistically significance only in groups moderate and severe. In these groups both WR and BMI have progressive increase and we believe that the latter could be a risk factor as important as WR/WPR.

\section{REFERENCES}

1. Johnson EW, Gatens T, Poindexter D, Bowers D. Wrist dimensions: correlation with median sensory latencies. Arch Phys Med Rehabil 1983;64:556-557.

2. Kuhlman KA, Hennessey WJ. Sensitivity and specificity of carpal tunnel syndrome signs. Am J Phys Med Rehabil 1997;76:451-457.

3. Bleecker ML, Bohlman M, Moreland R, Tipton. Carpal tunnel syndrome: role of carpal canal size. Neurology 1985;35:1599-1604.

4. Winn FJ, Habes DJ. Carpal tunnel area as a risk factor for carpal tunnel syndrome. Muscle Nerve 1990;13:254-258.

5. Gordon C, Johnson EW, Gatens PF, Ashton JJ. Wrist ratio correlation with carpal tunnel syndrome in industry. Am J Phys Med Rehabil 1988;67:270-272.

6. Edwards KS. Square wrists and carpal tunnel syndrome. Ohio Med 1990;86:432-433.

7. Stetson DS, Albers JW, Silverstein BA, Wolfe RA. Effects of age, sex, and anthropometric factors on nerve conduction measures. Muscle Nerve 1992;15:1095-1104.

8. Nathan PA, Keniston RC, Myers LD, Meadows KD. Obesity as a risk factor for slowing of sensory conduction of the median nerve in industry: a cross-sectional and longitudinal study involving 429 workers. J Occup Med 1992;34:379-383.

9. Radecki P. A gender specific wrist ratio and the likelihood of a median nerve abnormality at the carpal tunnel. Am J Med Rehabil 1994;73:157-162.

10. Radecki P. Variability in the median and ulnar nerve latencies: implications for diagnosing entrapment. J Occup Environ Med 1995;37:1293-1299.

11. Sposato RC, Riley MW, Ballard JL, Stentz TL, Glismann CL. Wrist squareness and median nerve impairment. J Occup Environ Med 1995;37:1122-1126.

12. Nakamichi K, Tachibana S. Small hand as a risk factor for idiopathic carpal tunnel syndrome. Muscle Nerve 1995;18:664-666. 